\title{
Review
}

Sylvain Lehmann*, Andrew Hoofnagle, Denis Hochstrasser, Cato Brede, Matthias Glueckmann, José A. Cocho, Uta Ceglarek, Christof Lenz, Jérôme Vialaret, Alexander Scherl and Christophe Hirtz on behalf of the IFCC Working Group on Clinical Quantitative Mass Spectrometry Proteomics (WG-cMSP)

\section{Quantitative Clinical Chemistry Proteomics (qCCP) using mass spectrometry: general characteristics and application}

\begin{abstract}
Proteomics studies typically aim to exhaustively detect peptides/proteins in a given biological sample. Over the past decade, the number of publications using proteomics methodologies has exploded. This was made possible due to the availability of high-quality genomic data and many technological advances in the fields of microfluidics and mass spectrometry. Proteomics in biomedical research was initially used in 'functional' studies for the identification of proteins involved in pathophysiological processes, complexes and networks. Improved sensitivity of instrumentation facilitated the analysis of even more complex sample types, including human biological fluids. It is at that point the field of clinical proteomics was born, and its fundamental aim was the discovery and (ideally) validation of biomarkers for the diagnosis, prognosis, or therapeutic monitoring of disease. Eventually, it was recognized that the technologies used in clinical proteomics studies [particularly liquid chromatography-tandem mass spectrometry (LC-MS/MS)] could represent an alternative to classical immunochemical assays. Prior to deploying MS in the measurement of peptides/proteins in the clinical laboratory, it seems likely that traditional proteomics workflows and data management systems will need to adapt to the clinical environment and meet in vitro diagnostic (IVD) regulatory constraints. This defines a new field, as reviewed in this article, that we have termed quantitative Clinical Chemistry Proteomics (qCCP).
\end{abstract}

Keywords: absolute quantification; Clinical Chemistry; mass spectrometry; peptides and proteins.

*Corresponding author: Sylvain Lehmann, CHU Montpellier, Institut de Recherche en Biothérapie, Hôpital St Eloi, Laboratoire de Biochimie Protéomique Clinique et CCBHM, Université
Montpellier 1, and INSERM U1040, 34000 Montpellier, France, E-mail:s-lehmann@chu-montpellier.fr

Andrew Hoofnagle: Departments of Laboratory Medicine and Medicine, University of Washington, Seattle, WA, USA

Denis Hochstrasser and Alexander Scherl: Biomedical Proteomics Research Group, Department of Human Protein Sciences, Faculty of Medicine, Geneva University, Geneva, Switzerland Denis Hochstrasser: Department of Genetic and Laboratory Medicine, Geneva University Hospitals, Geneva, Switzerland Cato Brede: Department of Medical Biochemistry, Stavanger University Hospital, Stavanger, Norway

Matthias Glueckmann: AB SCIEX Germany, GmbH, Darmstadt, Germany

José A. Cocho: Laboratorio de Metabolopatías, Hospital Clínico Universitario de Santiago, Santiago de Compostela, Spain Uta Ceglarek: Institute of Laboratory Medicine, Clinical Chemistry and Molecular Diagnostics, University Hospital Leipzig, Leipzig, Germany

Christof Lenz: Max-Planck-Institute for Biophysical Chemistry, Bioanalytical Mass Spectrometry Group, Goettingen, Germany Jérôme Vialaret and Christophe Hirtz: CHU Montpellier, Institut de Recherche en Biothérapie, Hôpital St Eloi, Laboratoire de Biochimie Protéomique Clinique et CCBHM, and Université Montpellier 1, and INSERM U1040, Montpellier, France

\section{Introduction}

The study of pathophysiological mechanisms is the basis of the selection/discovery of most clinical biomarkers used for the diagnosis or the monitoring of diseases. The ability to discover and use biomarkers is heavily dependent on technological developments to select, validate, and quantify them in biological fluids and tissues. Among these developments, we can cite the 'omics' technologies represented by genomics and the so-called post-genomics approaches (e.g., proteomics). Unbiased proteomics studies, which typically aim to exhaustively detect 
peptides/proteins in a given biological sample, were an important focus over the past decade [1]. This is explained by the availability of extensive genomic data, by technological advances in the field of micro- and nanotechnologies, and in the development of robust mass spectrometry (MS) methods [2]. Indeed, recent improvements in MS technology have achieved better sensitivity, specificity, and throughput. However, as with any innovative technology, translation from research to clinical use is a significant challenge [3]. Not only are there analytical considerations to be taken into account, but the feasibility of the approach in a hospital environment, the compliance with regulatory constraints, and the medical benefit vs. the monetary cost must also be considered. MS has demonstrated its clinical potential, e.g., in the field of small molecules, where its analytical capabilities and low cost have helped dethrone other approaches. In the area of quantitative analysis of peptides/proteins in biological fluids, which is the subject of this review, we believe that MS is poised to supplant traditional methods of immunochemical quantification of proteins. This will lead to a significant proliferation of methods to quantify biomarkers that will mark the start of a new field that we term quantitative Clinical Chemistry Proteomics (qCCP).

\section{General characteristics of qCCP}

qCCP, which must be viewed as a usable clinical application of the detection and quantification of proteins by MS, is easily differentiated from the other uses of MS in proteomics. To understand these differences, which go beyond purely analytical considerations, it might be interesting to review the history of the use of proteomics in the field of biology. In fact, once MS methods of peptides/proteins analysis were commonly available, the use first turned to the identification of proteins isolated during various biochemical purification, separation and fractionation methods. MS as a tool of identification has an essential role in biological research. This includes, e.g., the search for interacting protein partners [4], the analysis of biological complexes (e.g., transcriptional, enzymatic, signaling), and [5] most often following co-purification and separation with gel electrophoresis. Increases in MS sensitivity allowed one to focus on post-translational modifications (e.g., phosphorylation, oxidation) whose identification might help in the understanding of pathophysiological mechanisms.

The increase in sensitivity went hand in hand with more complete coverage of the proteome (i.e., the ability to detect low abundance proteins) [6], which led to the development of catalogs of proteins present in a given type of clinical sample (e.g., urine, serum, cerebrospinal fluid). However, the goal of being extensive is not necessarily useful from the perspective of clinical chemistry laboratories. Instead, in clinical proteomics, the different concentrations of peptides/proteins in normal vs. pathological conditions define new biomarkers. The technology used to identify differences in concentration is not important, but quantitative differences must be identifiable. Often proteomics experiments provide a relative quantification [7], strongly dependent on a series of experiments conducted in a short-time interval and in a specific analytical context. Experiments such as these have led to the identification of many potential biomarkers. Yet the vast majority of these biomarkers have never reached clinical use. It is not the purpose of this article to discuss this issue, but we can say that preanalytical biases, the relevance of initial clinical questions, the selection and phenotyping of patient groups, and the lack of appropriate validation phases are all elements that explain the poor success of the initially selected candidate biomarkers. As presented in this review, quantitative Clinical Chemistry Proteomics (qCCP) goes far beyond what has been previously termed 'clinical proteomics,' and has rigorous preanalytical, analytical and post-analytical constraints than enable the use of results in patient care. Of note, the expertise of the scientists involved in different stages of proteomic assay development is disparate; physicists for the design of machines; chemists who have used MS to quantify small molecules; basic science researchers interested in cataloging/the initial characterization of biological mixtures; those involved in the search for biomarkers; and finally clinical biologists (pathologists) trying to make qCCP a reality in patient care. All of these actors have different training/knowledge and sometimes there exist real difficulties in speaking a common language.

\section{qCCP workflow}

It is imperative that the final qCCP workflow parallels that of conventional analyses in clinical chemistry. As a result, one must immediately identify approaches, processes, and conditions that are compatible with a clinical setting for logistical, organizational, technical, and financial reasons. This is covered in great detail in section "Criteria for selecting analytes for qCCP”. A global vision of qCCP/ clinical workflow is illustrated in Figure 1. Indeed, the sample preparation in MS is only a part of a larger process 


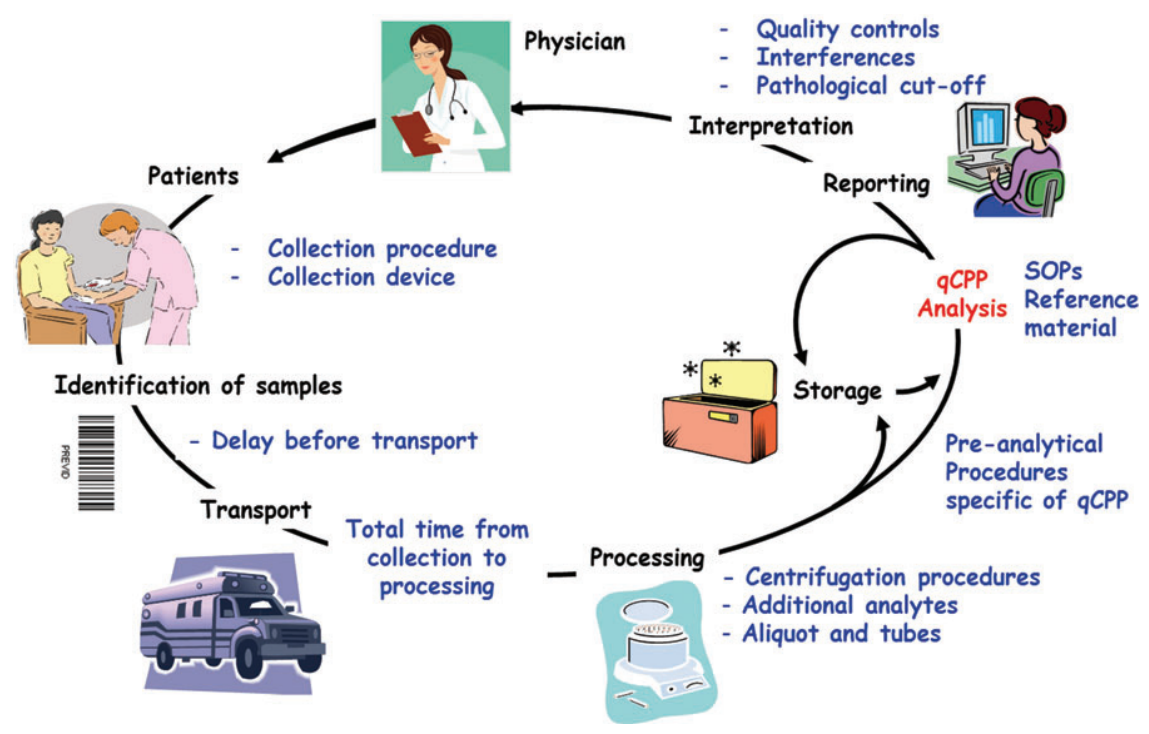

Figure 1 qCCP workflow.

qCCP workflow will need to parallel that of conventional analyses in clinical chemistry. This includes preanalytical steps from specimen collection to specimen handling to analysis that all need to comply with the IVD regulatory requirement and post-analytical steps for which normal and pathological values may need to be established.

in which each step is important. Any one step that causes variability or limited throughput and the entire procedure would be affected.

\section{Sample collection and initial preanalytics phases}

Clinical specimens, in particular serum or plasma, are collected using various types of tubes: with or without separator gel, with or without different types of anticoagulant, with different plastics. It is well-known that MS approaches can be sensitive to contaminants that are not relevant for classical immunological or enzymatic approaches [8]. As qCCP is a new way to use MS for clinical chemistry, it will be important to try to identify interferences that stem from the choice of collection devices. On the other end, if a given qCCP analysis would need particular handling, e.g., the addition of a protease inhibitor cocktail, or the minimization of the time between collections and processing, this would certainly impair its clinical utility. Blood contains cellular elements and a high protein content while other samples have less protein and high salt concentration. Therefore, a first step of clean-up by centrifugation, filtration, or even dialysis could be needed. Altogether, as for any clinical analysis, qCCP will have to follow standardized protocol compatible with common clinical workflows (Figure 1).

\section{Specific preanalytical procedures linked to qCCP}

Almost all qCCP analyses involve a method of pretreatment of complex samples that includes enzymatic digestion to generate proteotypic peptides [9] and/or prefractionation steps. The aim of the prefractionation is to reduce sample complexity and concentrate the analytes. There are various methods for the preparation of patient samples prior to analysis by MS [10]. The selection of the method relies primarily on the chemical characteristics of measured analytes (e.g., pI, hydrophobicity, and molecular weight), if the analytes are strongly bound to proteins, and the type of sample chosen for analysis (e.g., serum, urine). Several techniques have been described such as solid phase extraction (SPE), ion exchange, liquid-liquid extraction, depletion of major protein or immunocapture (see below). Whatever the sample matrix, to avoid interferences and errors, differences between the analytes and the matrix components will determine the choice of the prefractionation method.

\section{Enzymatic digestion}

For quantification of a protein, the qCCP method generally relies on the detection and quantification of one or several peptides originating from selected analyte as surrogates for the protein concentration. In most cases, samples are 
digested with trypsin, an enzyme that cleaves the protein specifically at the carboxyl end of the basic amino acids arginine and lysine [11]. The control of this step is critical to reduce variability linked to differential digestion between samples. Therefore, optimized protocols are needed to control enzyme-protein ratio, incubation time, composition of the digestion buffer and treatment preceding the digestion step (e.g., reduction with dithiothreitol and alkylation with iodoacetamide). Importantly, internal standards can have value in monitoring this critical step (see paragraph "Quantitative measurement, standard and reference material"). Direct analysis of the trypsin digest without additional sample fractionation is possible. This was the case in a work were 47 proteins were identified by direct analysis of signature peptides in trypsin digested plasma by liquid chromatography tandem MS (LC-MS/MS) with multiple reaction monitoring (MRM) [12]. Their concentrations ranged from $1 \mathrm{mg} / \mathrm{L}$ to $55 \mathrm{~g} / \mathrm{L}$ and approximate quantification was determined by using stable isotope-labeled standard (SIS) peptides [13]. Because validated external calibration curves and/or standard addition experiments were not performed, it is not clear how accurate these measurements were. More recently, by using ultra-high performance LC coupled with high sensitivity MS/MS, as many as 67 proteins were identified simultaneously, still without the need for additional sample fractionation [14]. These experiments need additional validation steps that would help clarify the accuracy of the approach; however, they were an important demonstration that potentially useful data could be obtained from serum using LC-MS/MS.

In at least one study, quantification of clinically useful biomarker proteins in plasma by multiplexed LC-MRM/MS has demonstrated promise in the absolute quantification of biomarkers in plasma [15]. Using external calibration and comparison with existing clinical immunoassays for ApoA-I and ApoB, the authors confirmed that the direct analysis of tryptic digests is a viable approach, and may someday offer a cost-efficient and sample-saving analysis method for the clinical laboratory.

\section{Protein precipitation}

When the proteins or peptides of interest are of low molecular weight, it may be possible to use simple protein precipitation for sample preparation. This approach takes advantage of the poor solubility of medium and large polypeptides in apolar solvents. It might be, however, difficult to standardize since variability can result from differences in total protein content of a given sample. By using a volatile solvent for precipitation, such as acetonitrile or acetone, the supernatant can be evaporated to produce a concentrated sample, thus improving analytical sensitivity. Other well-known precipitation reagents include trichloroacetic acid (TCA) and ammonium sulphate. Simple protein precipitation without trypsin cleavage has been used for biomarkers with clinical relevance (e.g., hepcidin-25 and insulin-like growth factor-1) [16, 17]. Depletion of high abundance proteins (HAP) by immunoaffinity extraction.

Blood may be an excellent sample for both discovering potential clinical biomarkers and for quantifying them clinically. However, the dynamic range of protein concentration is known to be up to 12 orders of magnitude and the quantification of low abundance proteins remains a tremendous analytical challenge. HAP are present at the $\mathrm{g} / \mathrm{L}$ level, with the most abundant being albumin (approx. $40 \mathrm{~g} / \mathrm{L}$ ). On the other end of the concentration scale lie the low abundance proteins or peptides, e.g., cytokines, which are present at low ng/L. One possible solution for improving the limits of detection of low abundance proteins is to deplete HAP by immobilized antibodies. There are commercially available low pressure LC type and spinfilter type columns with immobilized antibodies for as many as 20 HAP [18], making these products very popular in proteomics research for biomarker discovery [19]. Depletion of HAP may also be useful in qCCP, for improving the limits of detection of medium and low abundance proteins in clinical samples. HAP depletion has been reported to improve the reproducibility and increase the amount of sample that can be injected on column (approx. 6-fold) compared to a direct analysis of non-depleted plasma protein samples [12]. The removal of peptides from albumin and other high abundant proteins also improves chromatographic peak shape of the lower abundance analytes of interest. It must be, however, recognized that analytes of interest may variably bind abundant proteins removed by anti-HAP antibodies leading therefore to inaccuracy in measurement.

\section{Solid phase extraction}

Solid phase extraction (SPE) is a common sample preparation technique for biological fluids in analytical chemistry. It is based on adsorption chromatography with a range of chemical approaches ranging from simple hydrophobic or hydrophilic partition chromatography to ionexchange to immunoaffinity chromatography. It is a rapid sample preparation method used to selectively extract, 
concentrate and purify target analytes prior to LC-MS/MS analysis [20]. Interferences are selectively removed from the column during a wash step and analytes of interest are eluted in a highly enriched extract. This prefractionation method has been used in qCCP for small endogenous peptides like hepcidin and $\beta$-amyloid peptides without trypsin digestion (see Table 1).

\section{Analyte enrichment by immunoaffinity extraction}

Extraction by immunoaffinity adsorbents has also been used to enrich analytes of interest from samples prior to MS analysis. Immunocapture involves specific noncovalent binding interactions between antibodies and the protein or the peptide of interest [67]. The purified antibodies are immobilized on a solid support, such as porous agarose or magnetic beads. Complex samples (e.g., serum, urine) are added to the solid support and target molecules bind specifically to the immobilized antibodies. After washing away non-bound matrix components, the captured target molecules are released from the ligand using generally a low $\mathrm{pH}$ buffer. The use of immunocapture before MS may, however, not completely overcome the limitation of immunoassays, which often lack specificity in many human samples [68]. Importantly, MS can detect many isoforms at once, as in the detection of $\beta$-amyloid peptides in cerebrospinal fluid [69]. On-line immunoaffinity extraction coupled with reversed phase LC-MS which allows the re-use of the columns was also utilized with amyloid-related peptides [70] and human chorionic gonadotropin [71].

\section{qCCP quality control and quality assurance}

Clinical analyses must meet high-quality standards to ensure the quality of results delivered to care providers. To do this, one identifies and implements processes to avoid possible preanalytical errors that would cause the misidentification of samples or misleading results due to the conditions of specimen collection, specimen handling or specimen transfer. The integration of qCCP analyses into the laboratory management and information system could reduce these risks. The use of internal/external quality control is also essential. This helps ensure the quality of individual analyses but also allows longitudinal follow-up of patients. Proper clinical interpretation of qCCP results will depend on reference intervals, target ranges or medically relevant cut-off values based on control populations and variations due to pathophysiological processes of disease. Inaccuracies in qCCP measurement linked to interferences or lack of full specificity of the selected peptides need also to be considered.

For qCCP analyses, which could replace conventional immunochemical detection methods, concordance studies to confirm the equivalence of the results will facilitate their use. In a number of cases, comparison of qCCP measures using MS and those using conventional methods may demonstrate non-equivalence. Indeed, the absolute quantification that allows qCCP is likely to reveal inaccuracies/bias of other methods that are more susceptible to interferences or cross-reactivities. In these cases, as in cases where a new analyte will be measured by qCCP, a substantial number of samples from normal and pathological populations will need to be analyzed prior to clinical deployment.

\section{Analytical MS approaches for qCCP}

MS is an analytical technique that measures the mass ( $\mathrm{m}$ ) per charge ( $\mathrm{z}$ ) for a given ion (also termed the mass-tocharge ratio, $m / z$ ). This technique allows the quantification of ions of specific $m / z$, generally by comparison with an internal standard. Mass spectrometers can combine various ionization methods and different ion separation methodologies to achieve measurements of varying mass accuracy and assay precision.

\section{Matrix laser desorption ionization (MALDI) mass spectrometer}

This approach uses a laser beam to desorb and ionize a sample/matrix mixture co-crystalized on a surface. Matrix molecules as well as samples get ionized in the gas phase by absorbing the energy transmitted by the laser, which results in their eruption from the plate surface. This mode of ionization generates mainly singly charged molecules. Matrix laser desorption ionization (MALDI) can be combined with different MS methods [72], the most common being time-of-flight (TOF). TOF relies on an electric field to accelerate gas phase ions through a field-free path toward a detector. MALDI-TOF analyzers have a relatively unlimited $\mathrm{m} / \mathrm{z}$ range sensitivities and mass accuracies that 


\begin{tabular}{|c|c|c|c|c|}
\hline Analytes & Clinical interest & $\begin{array}{l}\text { Level of } \\
\text { development }\end{array}$ & Technology & References \\
\hline Brain natriuretic peptide (BNP-32) & $\begin{array}{l}\text { Clinical biomarker for the diagnosis, } \\
\text { prognosis and treatment of cardiac } \\
\text { insufficiency }(\mathrm{Cl})\end{array}$ & Clinical grade & FT-ICR & [21] \\
\hline C-reactive protein & $\begin{array}{l}\text { Marker for diagnosis of rheumatoid } \\
\text { arthritis (inflammation) }\end{array}$ & Clinical grade & QqQ & [22] \\
\hline Ceruloplasmin & $\begin{array}{l}\text { Inborn error of metabolism, copper } \\
\text { metabolism }\end{array}$ & Clinical grade & Q-TOF & [23] \\
\hline Collagen type II peptide & $\begin{array}{l}\text { Biomarker of osteoarthritis and } \\
\text { matrix metalloproteinase activity }\end{array}$ & Clinical grade & QqQ & [24] \\
\hline Glycohemoglobin $\left(\mathrm{HbA}_{1 \mathrm{c}}\right)$ & $\begin{array}{l}\text { Long-term monitoring of blood } \\
\text { glucose in diabetic patients }\end{array}$ & Clinical grade & ICP-MS, QqQ & [25-27] \\
\hline Hepcidin & $\begin{array}{l}\text { Biomarker of iron metabolism in } \\
\text { blood and urine }\end{array}$ & Clinical grade & $\begin{array}{l}\text { SELDI-TOF-MS } \\
\text { MALDI-TOF MS } \\
\text { Ion trap } \\
\text { QqQ }\end{array}$ & {$[16,28-36]$} \\
\hline $\begin{array}{l}\text { Human Serum Inter-Trypsin } \\
\text { Inhibitor Heavy Chain } 4 \text { (ITIH4) }\end{array}$ & Cancer biomarker & Research & $\begin{array}{l}\text { SELDI TOF } \\
\text { QqQ }\end{array}$ & {$[37,38]$} \\
\hline $\begin{array}{l}\text { Pro-gastrin-releasing peptide } \\
\text { (ProGRP) }\end{array}$ & $\begin{array}{l}\text { Diagnosis of bronchial cancer-small } \\
\text { cell cancer }\end{array}$ & Research & $\mathrm{Q}, \mathrm{QqQ}$ & [39] \\
\hline Xylosyltransferase I activity & $\begin{array}{l}\text { Biomarker for connective tissue } \\
\text { disease }\end{array}$ & Research & QqQ & [40] \\
\hline Urinary albumin & Biomarker of kidney function & Clinical grade & QqQ & [41] \\
\hline 45 Proteins in human plasma & $\begin{array}{l}\text { Plasma proteins including } \\
\text { biomarkers of cardiovascular } \\
\text { disease }\end{array}$ & Clinical grade & Q-TRAP & [42] \\
\hline $\begin{array}{l}\text { AHSG protein and AHSG } \\
\text { phosphopeptide }\end{array}$ & $\begin{array}{l}\text { Biomarker for hepatocellular } \\
\text { carcinoma }\end{array}$ & Research & $\begin{array}{l}\text { QqQ } \\
\text { Orbitrap }\end{array}$ & [43] \\
\hline $\begin{array}{l}\text { Amyloid peptides in cerebrospinal } \\
\text { fluid }\end{array}$ & Biomarkers of Alzheimer's disease & $\begin{array}{l}\text { Research and } \\
\text { clinical grade }\end{array}$ & $\begin{array}{l}\text { MALDI/SELDI } \\
\text { TOF } \\
\text { Ion trap, QqQ } \\
\text { Q-TRAP }\end{array}$ & [44-54] \\
\hline A-I and B Apolipoproteins & Cardiovascular risk prediction & Clinical grade & QqQ & [15] \\
\hline Apolipoprotein E (ApoE) & Cardiovascular risk/Alzheimer risk & $\begin{array}{l}\text { Research and } \\
\text { clinical grade }\end{array}$ & Ion trap & [55] \\
\hline $\begin{array}{l}\text { Bradykinin, fibrinogen fragments, } \\
\text { inter-trypsin inhibitor heavy chain } 4 \\
\text { and complement component } 4 a\end{array}$ & $\begin{array}{l}\text { Potential biomarkers for breast } \\
\text { cancer }\end{array}$ & Research & QqQ & [38] \\
\hline Cystatin C & Biomarker for kidney function & Research & Q-TOF & [56] \\
\hline Hemoglobin & Hemoglobinopathy & $\begin{array}{l}\text { Research and } \\
\text { clinical grade }\end{array}$ & ETD - Ion trap & [57] \\
\hline IGFBP-3 and IGF-1 & Hormone detection (abuse) & Research & $\begin{array}{l}\text { QqQ } \\
\text { QTRAP }\end{array}$ & {$[58,59]$} \\
\hline $\begin{array}{l}\text { NT-proBNP, MRP14, BNP-32, } \\
\text { Troponin I, CRP, sCD40L, IL-33, } \\
\text { Troponin T, MPO and Interleukin-33 }\end{array}$ & $\begin{array}{l}\text { Biomarkers of cardiovascular } \\
\text { disease }\end{array}$ & Research & $\begin{array}{l}\text { QqQ } \\
\text { Q-TRAP }\end{array}$ & {$[60,61]$} \\
\hline Oxytocin & Neuropeptide hormone & Research & QqQ & [62] \\
\hline $\begin{array}{l}\text { Proapolipoprotein A-I, transferrin, } \\
\text { hemoglobin, apolipoprotein } \\
\text { A-I, apolipoprotein C-III, and } \\
\text { haptoglobin a2chain }\end{array}$ & $\begin{array}{l}\text { Blood proteins including biomarkers } \\
\text { for breast cancer }\end{array}$ & Research & $\begin{array}{l}\text { MALDI-TOF/ } \\
\text { TOF }\end{array}$ & [63] \\
\hline Prostate specific antigen & Biomarker for prostate cancer & Clinical grade & Q-TRAP & {$[64,65]$} \\
\hline Zn- 2 glycoprotéine & $\begin{array}{l}\text { Potential biomarker for prostate } \\
\text { cancer }\end{array}$ & Research & QqQ & [66] \\
\hline
\end{tabular}

Table 1 Analytes that have been the subject of qCCP type analyses. 
decrease with increasing $\mathrm{m} / z$, and limited dynamic ranges (Table 2). Due to the complexity of biological fluids, this approach often necessitates efficient prefractionation/ purification of the analytes of interest before analysis. This has been done, e.g., for amyloid peptides following immunopurification [73].

A potentially interesting variation of MALDI-TOF is embodied by SELDI-TOF, which uses activated chromatographic surfaces [hydrophobic, hydrophilic, ion exchange, immobilized metal affinity chromatography (IMAC)] on chips to prefractionate protein samples before detection. This procedure selects a subset of the proteome based on physicochemical properties [74]. SELDI-TOF has a higher throughput than other methods of MS but it is limited by its poor ability to accurately and specifically detect low abundant proteins. It has been widely used to identify differences in the protein expression profiles of two or more distinct clinical samples and to quantify previously recognized biomarkers of disease. More specifically, immunocapture on the chips has been used to detect $\beta$-amyloid peptides in cerebrospinal fluid [44]. IMAC has been used to quantify hepcidin [75].

\section{Electrospray ionization (ESI) mass spectrometer}

This ionization method is based on the formation of droplets/spray at the end of the ESI capillary subjected to a high electrical potential. HPLC is used upfront to deliver a fractionated sample. HPLC relies on different types of stationary phases contained in columns and a pump system that moves the sample in a mobile phase through the column. In MS focused on peptides, a reversed phase HPLC column with a non-polar stationary phase and an aqueous, moderately polar mobile phase is generally used. Different pressures and flow rates are used, ranging from hundreds to $>10,000$ PSI and hundreds (normal flow) to $<1 \mu \mathrm{L} / \mathrm{min}$ (nano-flow), respectively. At the end of the capillary, an intense electric field ionizes molecules in progressively shrinking droplets (shrinkage due to solvent evaporation and Coulombic repulsion) ultimately leading to unsolvated protonated or deprotonated analyte ions. The ions that are generated, often with multiple charges, are guided using electrical potentials in a vacuum. Different MS systems separate ions based on $m / z$ via different mechanisms and detect them. In most cases relevant to qCCP, ionized analytes are fragmented by collision with a gas and the fragments are detected and quantified in an experiment termed tandem or MS/MS (or MS2) analysis.

\section{Ion trap}

Ion trap mass spectrometers analyze and fragment ions in the same space bounded generally by three electrodes. $A$ radio frequency with or without a continuous voltage tension is used to capture ions. A scan of the radio frequency amplitude leads to expulsion of ions with specific $\mathrm{m} / \mathrm{z}$ to a detector. MS2 analysis is possible after ion fragmentation using a radio frequency corresponding to ion resonance frequency. Resulting fragment ions are then trapped and can themselves be the subject of successive fragmentation $\left(\mathrm{MS}^{\mathrm{n}}\right)$. These systems are very efficient for the identification of peptides and were initially used in early qCCP studies (Table 1). The narrow dynamic range of ion trap mass spectrometers has generally limited their use in more recent qCCP efforts (Table 2). However, ion trapping devices offer the possibility to easily manipulate ions, such as performing ion-ion reactions. This opens news perspective for qCCP, such as the analysis of full-length proteins in an SRM-type of operation but with electron capture dissociation (ETD) instead of collisioninduced dissociation (CID) [31]. As illustrated in Figure 2, this approach can efficiently be used to address specific needs in qCCP.

\begin{tabular}{|c|c|c|c|c|c|c|c|}
\hline & $\begin{array}{l}\text { Triple Quadrupoles } \\
\text { (QqQ) }\end{array}$ & $\begin{array}{l}\text { Quadrupole } \\
\text { TOF (Q-TOF) }\end{array}$ & $\begin{array}{l}\text { Quadrupole } \\
\text { Orbitrap }\end{array}$ & Ion trap & Orbitrap & FT-ICR & $\begin{array}{l}\text { MALDI } \\
\text { TOF/TOF }\end{array}$ \\
\hline Selectivity/specificity & High & Very high & Very high & High & Very high & Very high & Very high \\
\hline Dynamic range & Very high & High & High & Low & Medium & Medium & Medium \\
\hline SRM/MRM & Very high & $\mathrm{n} / \mathrm{a}$ & High & High & $\mathrm{n} / \mathrm{a}$ & $\mathrm{n} / \mathrm{a}$ & $\mathrm{n} / \mathrm{a}$ \\
\hline Profile/Full scan & Low & Very high & Very high & low & High & Very high & $\mathrm{n} / \mathrm{a}$ \\
\hline Robustness & Very high & Medium & Medium & Very high & Medium & Medium & High \\
\hline Cost & +++ & ++++ & +++ & ++ & +++ & +++++ & +++ \\
\hline Use for qCCP & Very high & High & High & Low & Medium & Low & Low \\
\hline
\end{tabular}

Table 2 Mass spectrometer type and their characteristics with regards to qCCP. 

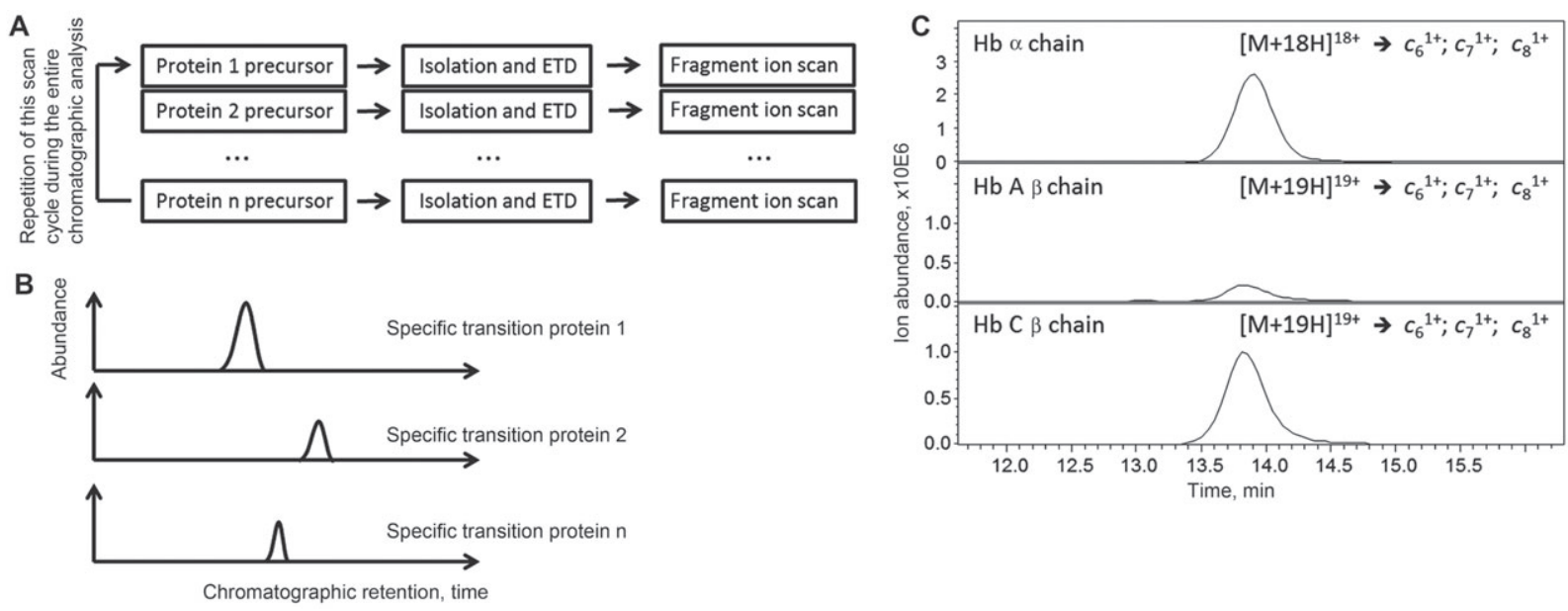

Figure 2 Principle and example of protein pseudo-SRM-ETD.

(A) In an ion trap, a fixed $\mathrm{m} / \mathrm{z}$ ratio corresponding to a multiply charged protein precursor ion is selected, isolated and activated with ETD, and the fragment ion spectrum is recorded. Next, an $\mathrm{m} / \mathrm{z}$ corresponding to another protein is selected, etc. With current instrument acquisition frequency, about five proteins can be monitored this way. B) Once the chromatographic analysis is terminated, specific fragment-ion chromatograms from specific precursor-ion channels are extracted. These chromatograms correspond to specific precursor $m / z-$ fragment ion $m / z$ transition, as in conventional SRM assays. However, as the full tandem mass spectra are acquired in time rather than a specific fragment ion signal in space like in conventional triple quadruple (QqQ) instruments, the method is referred to as pseudo-SRM [76]. C) The pseudo-SRM ETD assay is illustrated on human hemoglobin variants. The upper chromatogram shows a transition corresponding to the $\alpha$ chain of hemoglobin. The second chromatogram shows a transition specific to the non-mutated $\beta$ chain. The third chromatogram shows a transition specific to a mutated $\beta$ chain (Hemoglobin C, Glu6 $\rightarrow$ Lys). In this example, the patient is homozygote for hemoglobin C as no wild-type $\beta$ chain is detected. With this technique, subtle differences in full length protein sequences can be specifically tested. Although the $\beta$ chain of hemoglobin $C$ differs by only one Dalton from normal hemoglobin, both chains can be distinguished with high specificity using an ion trap device operating at nominal mass accuracy and resolution. The small interference observed in hemoglobin $A \beta$ chain corresponds to the second isotopic peak of hemoglobin $C$ fragments. To distinguish the two proteins at the precursor ion level, ultra-high resolution instrumentation would be necessary [57].

The quantitation of the amount of peptide/protein present in a biological sample in MS relies on the principle of isotope dilution. A known quantity of a stable isotope labeled internal standard might be added at different steps of the MS analytical workflow (see the text for details).

\section{Triple quadrupoles (ESI-QqQ)}

A single quadrupole (Q) is composed of four electrodes with a voltage potential difference that creates a quadrupolar electric field. By adjusting the voltage potentials between electrodes, one can control the trajectory of an ion entering the Q. Only ions with specific $\mathrm{m} / z$ will have a stable trajectory and reach the detector. Voltage scanning allows the detection of many ions across a wide mass range. QqQ mass spectrometers have two $\mathrm{Q}$ analyzers in series, separated by a collision cell, which has a slightly different design. This combination of Qs allows for simple MS experiments or in tandem experiments, which is the configuration most used in qCCP (Table 1). Briefly, the peptide of interest is selected in the first Q, fragmented in the second, and a specific fragment is detected after the third Q, which acts as a filter. This technology permits the highly sensitive, targeted detection and quantitation of a panel of peptides with very good selectivity, even in complex mixtures [77].

Of note, hybrid systems combining QqQ and ion trap (Q-TRAP) have been developed. These systems permit the specific quantitation of low abundant ions through an additional 'MS' fragmentation step in the ion trap. This approach in has been used to quantify prostate specific antigen (PSA) in non-depleted human serum with satisfactory linearity (10-1000 $\mu \mathrm{g} / \mathrm{L})$, sensitivity, and selectivity [64].

\section{ESI-Q-TOF}

These hybrid systems consist of a double Q (one analyzer and one collision cell) followed by a TOF device. The Qs in series provide for high MS/MS efficiency, while the TOF provides excellent mass accuracy/resolution and high speed of analysis. This represents a high-resolution MS system (HRMS) that makes it possible to obtain full scan precursor 
MS data at high resolution and also obtain peptide fragment data for identification. The high-resolution data have been used to compare the differences in peptide/protein quantities in body fluids and tissue samples in experiments that use either labeling or label free approaches (Table 1).

\section{Orbitrap}

This system includes two electrodes, one spindle-shaped placed coaxially inside another resulting in a quadrologarithmic electrostatic field. The current induced by ion oscillations generates a radio frequency that can be deconvolved into $m / z$ ion counts by Fourier transformation. This is comparable to Fourier transform ion cyclotron resonance (FTICR) MS, which is more precise but very expensive (to purchase and operate), therefore less compatible with qCCP. The orbitrap is a second example of HRMS. It is therefore possible to acquire full scan data of many precursor ions and then quantify specific fragments. Orbitraps are often placed in series with MS analyzers that have a faster cycle time. A hybrid system combining a quadrupole in front of an orbitrap system (Q-Orbitrap) is now available. This new approach with great potential is a way to combine the sensitivity of the $Q$ and the specificity of the orbitrap.

\section{Mass spectrometer system selection for qCCP}

Table 2 summarizes the main features of the analytical systems that can be used in qCCP. Looking at previous publications in the field (Table 1), we note that QqQ systems are most often used. They provide sensitive and selective detection of analytes, which is compatible with qCCP. The appearance of hybrid and HRMS systems with their multiplex potential represents an interesting development. Importantly, analytical performance of a system must be sufficient to handle the detection of analytes in complex samples, such as biological fluids, but many other factors are important (e.g., preanalytical variables, automation, coupling to HPLC, robustness). The dynamic signal range of the system, typically limited in TOF and ion traps when compared to Qs, is also a major issue especially with the perspective of multiplex analyses.

One additional issue is represented by the type of HPLC system since it will determine the throughput and the volume of sample used. Micro-HPLC systems are fast and reliable but need much higher volume of sample than capillary or nano-systems. The latter are very sensitive, they use very small volumes of samples, but they are less robust. The software environment, the data management system, the ability of the vendor to provide IVD-certified equipment and to ensure clinical grade service and maintenance are also important. Finally, based on our understanding of the hospital environment, it is likely that in the end, the choice of a system will not be on the pure analytical performance, but rather on the cost and capacity of the equipment and the availability of validated reagent kits that are clinically ready to use out-of-the-box.

\section{Quantitative measurement, standard and reference material}

\section{Quantitation and software}

MS quantitation can be performed by comparing samples after metabolic or chemical labeling using isotopes or tags [78]. This is not well-adapted to qCCP, where the goal is to have a robust and reproducible method that can apply on a large number of clinical samples. Label-free approaches have been widely used in biomarker discovery (pre-qCCP) experiments. One way to perform such quantitation is via comparison of signal intensities, peak areas, or the frequency of MS/MS events attributed to peptides of a given protein, an approach referred to as 'spectral counting' [79]. A considerable disadvantage of label-free quantification is its susceptibility to errors due to variability in HPLC/MS runs, its rather extensive workflow, and the statistical analyses that are required [80].

For proteomics and qCCP applications, software is needed that would allow MRM quantification of proteomics data while also utilizing factors such as: protein sequence, sequence annotation, functional annotation, public database of information like MS/MS spectra of detectable tryptic peptides, with peak areas, retention time, and internal standards. To achieve that, vendors propose software with various features that are generally restricted to the raw data from their own platforms. Alternatively, a public software called Skyline, is free and compatible with all vendors' file formats [80]. Skyline can be used to design SRM/MRM methods based on protein sequences and user-defined rules. It deals also with label-free methods [81]. It integrates SRM/MRM results to refine the initial method and can be used to compute absolute quantification based on calibration curves [82]. Skyline is getting the leading software as it facilitated 
incredible progress in the field of clinical proteomics and has brought qCCP closer to clinical laboratories than any other software advance.

\section{Absolute quantification strategies}

From a clinical perspective, it is important to achieve absolute quantitation of the amount of peptide/protein present in a biological sample. Isotope dilution is probably the method of choice for qCCP, because it includes the addition to the sample of a known quantity of an internal standard only modified by the incorporation of stable isotopes (e.g., 13C, 15N) (Figure 2).

One approach uses stable isotope-labeled standard (SIS) peptides $[13,83]$ as internal standards (Figure 3). Typically, after the tryptic digestion of sample, SIS peptides are added in known quantities. Native and SIS peptides are detected at roughly the same retention time and have comparable ionization properties, but are easily distinguished by the difference in mass due to isotopic labeling.

The amount of native peptide in a tryptic digest can be determined from the intensity ratio to the SIS peptide present in known quantities using external calibration. To help confirm the quantification, a second peptide from the same protein could be quantified simultaneously. This

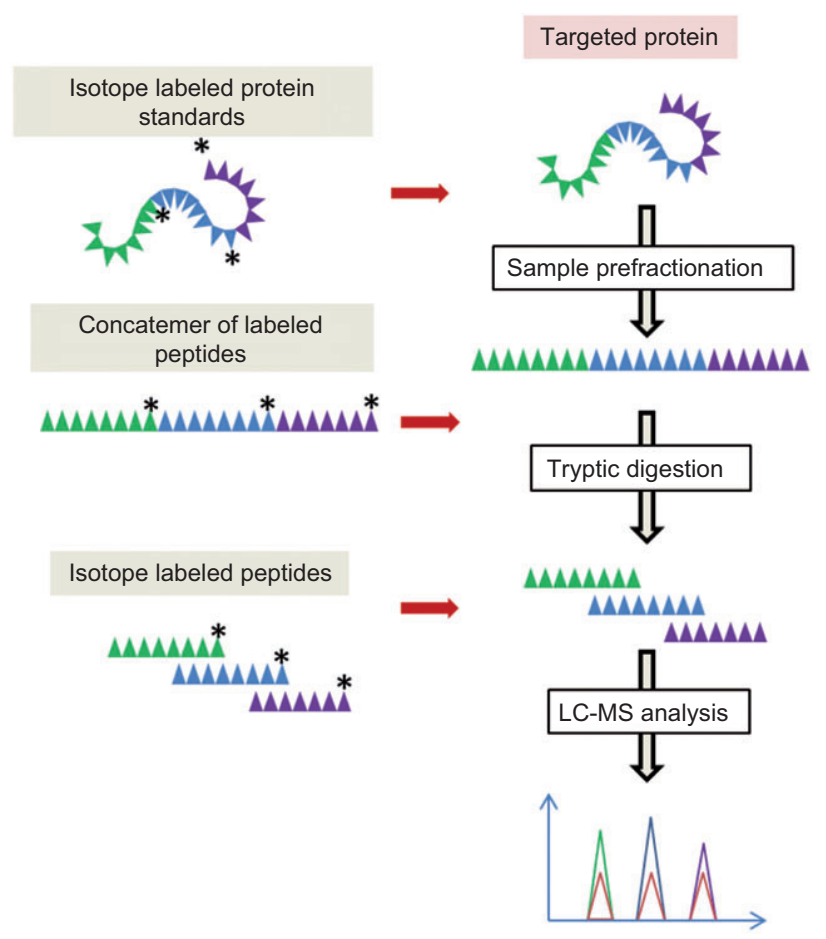

Figure 3 Absolute quantification strategies. approach has been widely used for the quantification of proteins following enzymatic digestion [15, 21, 60]. Such SIS peptides are produced by chemical synthesis and are readily available commercially, which explains the ease of implementation of this method.

The SIS approach has however limitations, mainly due to the fact that SIS peptides added in the final phase of sample preparation correct for bias in the analytical measurement and not throughout sample preparation (notably, during enzymatic digestion). An alternative approach attempts to control for variability at the digestion step using a prokaryotic expression system (Escherichia coli) and stable isotope-labeled amino acids to express a protein corresponding to the concatamer of the tryptic peptides of interest [84]. This polypeptide sequence is then added to the sample prior to tryptic digestion (Figure 3). One can then use the liberated peptides from the concatamer as internal standards, an approach therefore particularly well-suited for multiplexed analysis of many proteins [12]. However, the method is still subject to the potential bias in that a partial synthetic polypeptide sequence may not be digested similar to a complete protein. Differences in denaturation could lead to retained secondary structure or protein-protein interactions. Otherwise, it is possible to use isotopically-labeled whole proteins which are more biochemically similar to the endogenous targets. They can be synthesized in culture [85] or in 'CellFree' paradigms [86], purified, and then added prior to any treatment of the sample (Figure 3). This approach can theoretically help control for variability at all steps in the process except that variability that is due to post-translational modifications not present in the expression systems.

\section{Criteria for selecting analytes for qCCP}

The choice of a target analyte for qCCP must meet many criteria related to patient sampling, analytical conditions, medical benefit and monetary cost. Our consideration will be based on the hypothesis that qCPP will be implemented in a large number of laboratories and for a significant number of patients.

\section{Preanalytical and pretreatment issues, analytical/medical/economic issues}

As mentioned previously it is important that the qCCP analysis be compatible with most routine analyses of patient samples. In other words the preanalytical processes needed to achieve satisfactory analytical values (e.g., reproducibility, limit of detection/quantitation) 
need to resemble those required for the analytes already measured in biological fluids of interest (i.e., blood, urine, etc.). For example, the need for a specific collection tube containing proteinase/phosphatase inhibitors, or antioxidants could have a strong negative impact on the cost of analysis and may make qCCP for that analyte unfeasible.

\section{Analytical issues}

It is clear that qCCP analyses must reach a satisfactory level of analytical performance in terms of repeatability, robustness, reproducibility, and limits of detection. These features are often measured in research laboratories and on different proteomic platforms. However, there is a risk that these data will not be repeated in clinical laboratories. In most cases these data are generated on samples whose diversity and preanalytical sample handling do not represent the real-life situation. There is therefore a large under-estimation of the impact of inevitable preanalytical variations (i.e., time of processing, refrigeration, hemolysis, etc.) and of individual biological variations present in routine, uncontrolled, clinical samples (presence of inflammatory syndromes, dysglobulinemia, hyper-, hypoproteinemia, hemolysis, presence of xenobiotics, etc.).

With regard to the analytical performance in terms of sensitivity, there is also a huge gap between what is sought in a laboratory focusing on functional proteomics and a hospital laboratory. For clinical analytes we need to measure concentrations in pathophysiological ranges with satisfactory reproducibility, robustness and linearity. The detection of concentrations well below physiological concentrations is often unnecessary and one would rather select methods that have less front-end sample preparation (e.g., avoid concentration or dilution steps).

Of course, the medical utility of the assay must also be evaluated. As mentioned previously, in cases where the analyte is already measured with another method, it is possible to use the available information in terms of population values and thresholds after concordance studies and analyses using Bland and Altman plots [87] and weighted Deming regression.

\section{Conclusions and perspective}

There is no doubt that present and future technological developments in MS will allow the quantification of single or many peptides/proteins in complex biological fluids by qCCP methods that meet the rigorous quality standards set by the clinical environment. This will be facilitated by important knowledge generated in relevant Human Proteome Organisation (HUPO) sponsored scientific initiatives. Working groups of the International Federation of Clinical Chemistry and Laboratory Medicine (IFCC), and in particular the one on Clinical Quantitative Mass Spectrometry Proteomics (WG-cMSP) will also help in particular regarding standardization issues. The choice of whether to develop/use qCCP for a series of clinical analytes then becomes the critical issue. Asked another way, is there value added in using a qCCP analysis rather than using another available and more common approach? We list below some of the reasons:

1. If the analysis of a clinical biomarker requires impractical preanalytical processes or has issues in terms of laboratory safety (e.g., radioimmunoassay).

2. If existing assay methods have non-optimal sensitivity or specificity that limit clinical utility. This may be in relation with the biochemical characteristic of the analytes (e.g., poor immunogenicity, high assay crossreactivity with other analytes from a same family).

3. If there is an interest to include several isoforms of a given analyte. For example, the detection of polymorphisms (like for ApoE) or post-translational modifications (as for $\beta$-amyloid peptides) could be meaningful.

4. If intellectual property concerns limit the availability of reagents or greatly inflate the cost of analysis.

5. If there is added value in integrating data from a panel of several analytes (i.e., qCCP approaches can be easily multiplexed compared with immunological approaches).

6. If novel biomarkers do have not existing immunedetection methods readily available (it is likely less expensive to develop a qCCP assay than an immunochemical assay on an automated analyzer).

The implementation of qCCP is ongoing with several groups developing clinical applications for particular analytes (e.g., hepcidin, amyloid peptides, hemoglobin, apolipoproteins). This is not an easy task but this will be the first step in the expansion of a new MS approach which will represent, as in other clinical areas, a major analytical advance.

\section{Highlights}

- MS is the leading analytical approach in proteomics.

- Technological developments in MS increase analytical sensitivity and specificity to improve the quantitation of clinical analytes in biological fluids. 
- Different MS systems (e.g., MALDI-TOF, QqQ, Q-TOF and Orbitrap) with different characteristics are compatible with and have been used for the quantitative detection of clinical analytes.

- The use of MS for the quantitative detection of clinically relevant peptide/protein biomarkers in biological fluids will need to comply with IVD requirements and, which could be defined as a new field called quantitative Clinical Chemistry Proteomics (qCCP).

- The choice of analytes to be handled by qCCP relies on many factors: feasibility of the analysis in a clinical environment, medical/economic considerations, validation of normal reference intervals or pathological cut-offs, availability of quality controls and standard material, etc.

\section{Expert opinion}

There is no doubt that present and future technological developments in MS will allow proteomics workflows to quantify single and multiple analytes in complex biological fluids in a manner that is robust and accurate enough to be considered adequate in clinical chemistry laboratories. This will, however, necessitate adapted preparative methods, efficient quality control and standardization. The choice to develop/use qCCP for a series of clinical analytes relies on several factors including: the replacement of existing analyses for analytical or economic issues; the capacity to detect novel biomarkers/isoforms that lack satisfactory immunochemical detection methods; or the development of panels of several relevant clinical analytes. The implementation of the first qCCP analyses is ongoing, and one can expect an expansion of this new MS approach in the near future.

Acknowledgments: This review was generated as a task of the International Federation of Clinical Chemistry (IFCC) working group on Clinical Quantitative Mass Spectrometry Proteomics (WG-cMSP).

\section{Conflict of interest statement}

Authors' conflict of interest disclosure: The authors stated that there are no conflicts of interest regarding the publication of this article.

Research funding: None declared.

Employment or leadership: None declared.

Honorarium: None declared.

Several authors or members of the IFCC working group (cMSP) belong to the companies selling mass spectrometry equipment. To avoid conflict of interest, these authors provided only commercially available technical information on their system and they contributed mostly to the general section of this article (and not to the introduction, conclusion, perspective and expert opinion). of note, this review article does not give recommendation in favor of a particular technology or system which reduces the risk of conflict of interest.

Received August 28,2012; accepted October 22,2012; previously published online November 23, 2012

\section{References}

1. James P. Protein identification in the post-genome era: the rapid rise of proteomics. Q Rev Biophys 1997;30:279-331.

2. Aebersold R, Mann M. Mass spectrometry-based proteomics. Nature 2003;422:198-207.

3. Rifai N, Gillette MA, Carr SA. Protein biomarker discovery and validation: the long and uncertain path to clinical utility. Nat Biotechnol 2006;24:971-83.

4. Stengel F, Aebersold R, Robinson CV. Joining forces: integrating proteomics and cross-linking with the mass spectrometry of intact complexes. Mol Cell Proteomics 2012;11:R111 014027.

5. Gingras AC, Aebersold R, Raught B. Advances in protein complex analysis using mass spectrometry. J Physiol 2005;563:11-21.

6. Thakur SS, Geiger T, Chatterjee B, Bandilla P, Frohlich F, Cox J, et al. Deep and highly sensitive proteome coverage by LC-MS/ MS without prefractionation. Mol Cell Proteomics 2011;10:M110 003699.

7. Lundgren DH, Hwang SI, Wu L, Han DK. Role of spectral counting in quantitative proteomics. Expert Rev Proteomics 2010;7:39-53.
8. Ji SQ, Evenson MA. Effects of contaminants in blood-collection devices on measurements of therapeutic drugs. Clin Chem 1983;29:456-61.

9. Craig R, Cortens JP, Beavis RC. The use of proteotypic peptide libraries for protein identification. Rapid Commun Mass Spectrom 2005;19:1844-50.

10. Ewles M, Goodwin L. Bioanalytical approaches to analyzing peptides and proteins by LC-MS/MS. Bioanalysis 2011;3: 1379-97.

11. Olsen JV, Ong SE, Mann M. Trypsin cleaves exclusively C-terminal to arginine and lysine residues. Mol Cell Proteomics 2004;3:608-14.

12. Anderson L, Hunter CL. Quantitative mass spectrometric multiple reaction monitoring assays for major plasma proteins. Mol Cell Proteomics 2006;5:573-88.

13. Mayya V, Han DK. Proteomic applications of protein quantification by isotope-dilution mass spectrometry. Expert Rev Proteomics 2006;3:597-610. 
14. Domanski D, Percy AJ, Yang J, Chambers AG, Hill JS, Freue GV, et al. MRM-based multiplexed quantitation of 67 putative cardiovascular disease biomarkers in human plasma. Proteomics 2012;12:1222-43.

15. Agger SA, Marney LC, Hoofnagle AN. Simultaneous quantification of apolipoprotein A-I and apolipoprotein B by liquid-chromatography-multiple- reaction-monitoring mass spectrometry. Clin Chem 2010;56:1804-13.

16. Bansal SS, Abbate V, Bomford A, Halket JM, Macdougall IC, Thein SL, et al. Quantitation of hepcidin in serum using ultrahigh-pressure liquid chromatography and a linear ion trap mass spectrometer. Rapid Commun Mass Spectrom 2010;24:1251-9.

17. Bystrom CE, Sheng S, Clarke NJ. Narrow mass extraction of time-of-flight data for quantitative analysis of proteins: determination of insulin-like growth factor-1. Anal Chem 2011;83:9005-10.

18. Roche S, Tiers L, Provansal M, Seveno M, Piva MT, Jouin P, et al. Depletion of one, six, twelve or twenty major blood proteins before proteomic analysis: the more the better? J Proteomics 2009;72:945-51.

19. Smith MP, Wood SL, Zougman A, Ho JT, Peng J, Jackson D, et al. A systematic analysis of the effects of increasing degrees of serum immunodepletion in terms of depth of coverage and other key aspects in top-down and bottom-up proteomic analyses. Proteomics 2011;11:2222-35.

20. Callesen AK, Madsen JS, Vach W, Kruse TA, Mogensen O, Jensen ON. Serum protein profiling by solid phase extraction and mass spectrometry: a future diagnostics tool? Proteomics 2009;9:1428-41.

21. Hawkridge AM, Heublein DM, Bergen HR 3rd, Cataliotti A, Burnett JC Jr., Muddiman DC. Quantitative mass spectral evidence for the absence of circulating brain natriuretic peptide (bnp-32) in severe human heart failure. Proc Natl Acad Sci USA 2005;102:17442-7.

22. Kuhn E, Wu J, Karl J, Liao H, Zolg W, Guild B. Quantification of c-reactive protein in the serum of patients with rheumatoid arthritis using multiple reaction monitoring mass spectrometry and 13c-labeled peptide standards. Proteomics 2004;4:1175-86.

23. deWilde A, Sadilkova K, Sadilek M, Vasta V, Hahn SH. Tryptic. peptide analysis of ceruloplasmin in dried blood spots using liquid chromatography-tandem mass spectrometry: application to newborn screening. Clin Chem 2008;54:1961-8.

24. Li WW, Nemirovskiy O, Fountain S, Rodney Mathews W, SzekelyKlepser G. Clinical validation of an immunoaffinity LC-MS/MS assay for the quantification of a collagen type II neoepitope peptide: a biomarker of matrix metalloproteinase activity and osteoarthritis in human urine. Anal Biochem 2007;369:41-53.

25. del Castillo E, Montes-Bayon M, Anon E, Sanz-Medel A. Quantitative targeted biomarker assay for glycated haemoglobin by multidimensional LC using mass spectrometric detection. J Proteomics 2010;74:35-43.

26. Kaiser P, Akerboom T, Ohlendorf R, Reinauer H. Liquid chromatography-isotope dilution-mass spectrometry as a new basis for the reference measurement procedure for hemoglobin A1c determination. Clin Chem 2010;56:750-4.

27. Jeppsson JO, Kobold U, Barr J, Finke A, Hoelzel W, Hoshino T, et al. Approved IFCC reference method for the measurement of HbA1c in human blood. Clin Chem Lab Med 2002;40:78-89.

28. Anderson DS, Kirchner M, Kellogg M, Kalish LA, Jeong JY, Vanasse G, et al. Design and validation of a high-throughput matrix-assisted laser desorption ionization time-of-flight mass spectrometry method for quantification of hepcidin in human plasma. Anal Chem 2011;83:8357-62.

29. Bansal SS, Halket JM, Bomford A, Simpson RJ, Vasavda N, Thein SL, et al. Quantitation of hepcidin in human urine by liquid chromatography-mass spectrometry. Anal Biochem 2009;384:245-53.

30. Bansal SS, Halket JM, Fusova J, Bomford A, Simpson RJ, Vasavda N, et al. Quantification of hepcidin using matrixassisted laser desorption/ionization time-of-flight mass spectrometry. Rapid Commun Mass Spectrom 2009; 23:1531-42.

31. Bozzini C, Campostrini N, Trombini P, Nemeth E, Castagna A, Tenuti I, et al. Measurement of urinary hepcidin levels by SELDI-TOF-MS in HFE-hemochromatosis. Blood Cells Mol Dis 2008;40:347-52.

32. Hwang SI, Lee YY, Park JO, Norton HJ, Clemens E, Schrum LW, et al. Effects of a single dose of oral iron on hepcidin concentrations in human urine and serum analyzed by a robust LC-MS/MS method. Clin Chim Acta 2011;412:2241-7.

33. Houbart V, Cobraiville G, Lecomte F, Debrus B, Hubert P, Fillet M. Development of a nano-liquid chromatography on chip tandem mass spectrometry method for high-sensitivity hepcidin quantitation. J Chromatogr A 2011;1218:9046-54.

34. Kroot J), Kemna EH, Bansal SS, Busbridge M, Campostrini N, Girelli D, et al. Results of the first international round robin for the quantification of urinary and plasma hepcidin assays: need for standardization. Haematologica 2009;94:1748-52.

35. Li N, Palandra J, Nemirovskiy OV, Lai Y. LC-MS/MS mediated absolute quantification and comparison of bile salt export pump and breast cancer resistance protein in livers and hepatocytes across species. Anal Chem 2009;81:2251-9.

36. Murphy AT, Witcher DR, Luan P, Wroblewski VJ. Quantitation of hepcidin from human and mouse serum using liquid chromatography tandem mass spectrometry. Blood 2007;110:1048-54.

37. Song J, Patel M, Rosenzweig CN, Chan-Li Y, Sokoll LJ, Fung ET, et al. Quantification of fragments of human serum inter-alphatrypsin inhibitor heavy chain 4 by a surface-enhanced laser desorption/ionization-based immunoassay. Clin Chem 2006;52:1045-53.

38. van den Broek I, Sparidans RW, Schellens JH, Beijnen JH. Quantitative assay for six potential breast cancer biomarker peptides in human serum by liquid chromatography coupled to tandem mass spectrometry. J Chromatogr B Analyt Technol Biomed Life Sci 2010;878:590-602.

39. Winther B, Moi P, Paus E, Reubsaet JL. Targeted determination of the early stage SCLC specific biomarker pro-gastrin-releasing peptide (progrp) at clinical concentration levels in human serum using LC-MS. J Sep Sci 2007;30:2638-46.

40. Kuhn J, Prante C, Schon S, Gotting C, Kleesiek K. Measurement of fibrosis marker xylosyltransferase I activity by HPLC. electrospray ionization tandem mass spectrometry. Clin Chem 2006;52:2243-9.

41. Seegmiller JC, Sviridov D, Larson TS, Borland TM, Hortin GL, Lieske JC. Comparison of urinary albumin quantification by. immunoturbidimetry, competitive immunoassay, and protein cleavage liquid chromatography-tandem mass spectrometry. Clin Chem 2009;55:1991-4.

42. Kuzyk MA, Smith D, Yang J, Cross TJ, Jackson AM, Hardie DB, et al. Multiple reaction monitoring-based, multiplexed, 
absolute quantitation of 45 proteins in human plasma. Mol Cell Proteomics 2009;8:1860-77.

43. Lee HJ, Na K, Kwon MS, Kim H, Kim KS, Paik YK. Quantitative analysis of phosphopeptides in search of the disease biomarker from the hepatocellular carcinoma specimen. Proteomics 2009;9:3395-408.

44. Lewczuk P, Esselmann H, Groemer TW, Bibl M, Maler JM, Steinacker $P$, et al. Amyloid $\beta$ peptides in cerebrospinal fluid as profiled with surface enhanced laser desorption/ionization time-of-flight mass spectrometry: evidence of novel biomarkers in Alzheimer's disease. Biol Psychiatry 2004;55:524-30.

45. Thompson AJ, Lim TK, Barrow CJ. On-line high-performance liquid chromatography/mass spectrometric investigation of amyloid- $\beta$ peptide variants found in Alzheimer's disease. Rapid Commun Mass Spectrom 1999;13:2348-51.

46. Albertini V, Bruno A, Paterlini A, Lista S, Benussi L, Cereda C, et al. Optimization protocol for amyloid- $\beta$ peptides detection in human cerebrospinal fluid using SELDI TOF MS. Proteomics Clin Appl 2010;4:352-7.

47. Maddalena AS, Papassotiropoulos A, Gonzalez-Agosti C, Signorell A, Hegi T, Pasch T, et al. Cerebrospinal fluid profile of amyloid $\beta$ peptides in patients with Alzheimer's disease determined by protein biochip technology. Neurodegener Dis 2004;1:231-5.

48. Du C, Ramaley C, McLean H, Leonard SC, Miller J. High-performance liquid chromatography coupled with tandem mass spectrometry for the detection of amyloid $\beta$ peptide related with Alzheimer's disease. J Biomol Tech 2005;16:356-63.

49. Oe T, Ackermann BL, Inoue K, Berna MJ, Garner CO, Gelfanova V, et al. Quantitative analysis of amyloid $\beta$ peptides in cerebrospinal fluid of Alzheimer's disease patients by immunoaffinity purification and stable isotope dilution liquid chromatography/negative electrospray ionization tandem mass spectrometry. Rapid Commun Mass Spectrom 2006;20:3723-35.

50. Ford MJ, Cantone JL, Polson C, Toyn JH, Meredith JE, Drexler DM. Qualitative and quantitative characterization of the amyloid beta peptide $(A \beta)$ population in biological matrices using an immunoprecipitation-LC/MS assay. J Neurosci Methods 2008;168:465-74.

51. Grasso $\mathrm{G}$. The use of mass spectrometry to study amyloid- $\beta$ peptides. Mass Spectrom Rev 2011;30:347-65.

52. Lame ME, Chambers EE, Blatnik M. Quantitation of amyloid $\beta$ peptides $A \beta$ in human cerebrospinal fluid by ultra-performance liquid chromatography-tandem mass spectrometry. Anal Biochem 2011;419:133-9.

53. Varesio E, Rudaz S, Krause KH, Veuthey JL. Nanoscale liquid chromatography and capillary electrophoresis coupled to electrospray mass spectrometry for the detection of amyloid- $\beta$ peptide related to Alzheimer's disease. J Chromatogr A 2002;974:135-42.

54. Portelius E, Brinkmalm G, Tran A, Andreasson U, Zetterberg H, Westman-Brinkmalm A, et al. Identification of novel N-terminal fragments of amyloid precursor protein in cerebrospinal fluid. Exp Neurol 2010;223:351-8.

55. Wildsmith KR, Han B, Bateman RJ. Method for the simultaneous quantitation of apolipoprotein $\mathrm{E}$ isoforms using tandem mass spectrometry. Anal Biochem 2009;395:116-8.

56. Storme ML, Sinnaeve BA, Van Bocxlaer JF. The use of tryptic marker-peptides for the quantitative analysis of cystatin C. J Sep Sci 2005;28:1759-63.
57. Coelho Graca D, Lescuyer P, Clerici L, Tsybin YO, Hartmer R, Meyer $\mathrm{M}$, et al. Electron transfer dissociation mass spectrometry of hemoglobin on clinical samples. J Am Soc Mass Spectrom 2012;23:1750-6.

58. Bredehoft M, Schanzer W, Thevis M. Quantification of human insulin-like growth factor-1 and qualitative detection of its analogues in plasma using liquid chromatography/electrospray ionisation tandem mass spectrometry. Rapid Commun Mass Spectrom 2008;22:477-85.

59. Kirsch S, Widart J, Louette J, Focant JF, De Pauw E. Development of an absolute quantification method targeting growth hormone biomarkers using liquid chromatography coupled to isotope dilution mass spectrometry. J Chromatogr A 2007;1153:300-6.

60. Keshishian H, Addona T, Burgess M, Mani DR, Shi X, Kuhn E, et al. Quantification of cardiovascular biomarkers in patient plasma by targeted mass spectrometry and stable isotope dilution. Mol Cell Proteomics 2009;8:2339-49.

61. Kuhn E, Addona T, Keshishian H, Burgess M, Mani DR, Lee RT, et al. Developing multiplexed assays for troponin I and interleukin-33 in plasma by peptide immunoaffinity enrichment and targeted mass spectrometry. Clin Chem 2009;55:1108-17.

62. Zhang G, Zhang Y, Fast DM, Lin Z, Steenwyk R. Ultra sensitive quantitation of endogenous oxytocin in rat and human plasma using a two-dimensional liquid chromatography-tandem mass spectrometry assay. Anal Biochem 2011;416:45-52.

63. Huang HL, Stasyk T, Morandell S, Dieplinger H, Falkensammer G, Griesmacher A, et al. Biomarker discovery in breast cancer serum using 2-D differential gel electrophoresis/MALDI-TOF/TOF and data validation by routine clinical assays. Electrophoresis 2006;27:1641-50

64. Fortin T, Salvador A, Charrier JP, Lenz C, Bettsworth F, Lacoux X, et al. Multiple reaction monitoring cubed for protein quantification at the low nanogram/milliliter level in nondepleted human serum. Anal Chem 2009;81:9343-52.

65. Fortin T, Salvador A, Charrier JP, Lenz C, Lacoux X, Morla A, et al. Clinical quantitation of prostate-specific antigen biomarker in the low nanogram/milliliter range by conventional bore liquid chromatography-tandem mass spectrometry (multiple reaction monitoring) coupling and correlation with ELISA tests. Mol Cell Proteomics 2009;8:1006-15.

66. Bondar OP, Barnidge DR, Klee EW, Davis BJ, Klee GG. LC-MS/ MS quantification of $Z n-\alpha 2$ glycoprotein: a potential serum biomarker for prostate cancer. Clin Chem 2007;53:673-8.

67. Anderson NL, Anderson NG, Haines LR, Hardie DB, Olafson RW, Pearson TW. Mass spectrometric quantitation of peptides and proteins using stable isotope standards and capture by anti-peptide antibodies (SISCAPA). J Proteome Res 2004;3: 235-44.

68. Hoofnagle AN, Wener MH. The fundamental flaws of immunoassays and potential solutions using tandem mass spectrometry. J Immunol Methods 2009;347:3-11.

69. Portelius E, Zetterberg H, Gobom J, Andreasson U, Blennow K. Targeted proteomics in Alzheimer's disease: focus on amyloid- $\beta$. Expert Rev Proteomics 2008;5:225-37.

70. Sen JW, Bergen HR 3rd, Heegaard NH. On-line immunoaffinityliquid chromatography-mass spectrometry for identification of amyloid disease markers in biological fluids. Anal Chem 2003;75:1196-202.

71. Gam LH, Tham SY, Latiff A. Immunoaffinity extraction and tandem mass spectrometric analysis of human chorionic 
gonadotropin in doping analysis. J Chromatogr B Analyt Technol Biomed Life Sci 2003;792:187-96.

72. Rathore R, Corr JJ, Lebre DT, Seibel WL, Greis KD. Extending matrix-assisted laser desorption/ionization triple quadrupole mass spectrometry enzyme screening assays to targets with small molecule substrates. Rapid Commun Mass Spectrom 2009;23:3293-300.

73. Portelius E, Dean RA, Gustavsson MK, Andreasson U, Zetterberg $\mathrm{H}$, Siemers $\mathrm{E}$, et al. A novel $A \beta$ isoform pattern in CSF reflects $\gamma$-secretase inhibition in Alzheimer disease. Alzheimers Res Ther 2010;2:7.

74. Merchant M, Weinberger SR. Recent advancements in surfaceenhanced laser desorption/ionization-time of flight-mass spectrometry. Electrophoresis 2000;21:1164-77.

75. Ward DG, Roberts K, Stonelake P, Goon P, Zampronio CG, Martin A, et al. SELDI-TOF-MS determination of hepcidin in clinical samples using stable isotope labelled hepcidin as an internal standard. Proteome Sci 2008;6:28.

76. Scherl A, Shaffer SA, Taylor GK, Kulasekara HD, Miller SI, Goodlett DR. Genome-specific gas-phase fractionation strategy. for improved shotgun proteomic profiling of proteotypic. peptides. Anal Chem 2008;80:1182-91.

77. Lange V, Picotti P, Domon B, Aebersold R. Selected reaction monitoring for quantitative proteomics: a tutorial. Mol Syst Biol 2008; 4:222.

78. Brewis IA, Brennan P. Proteomics technologies for the global. identification and quantification of proteins. Adv Protein Chem Struct Biol 2010;80:1-44.

79. Bantscheff M, Schirle M, Sweetman G, Rick J, Kuster B. Quantitative mass spectrometry in proteomics: a critical review. Anal Bioanal Chem 2007;389:1017-31.

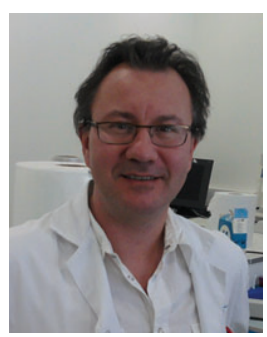

Prof. Sylvain Lehmann was trained as an M.D./Ph.D. (1992, Strasbourg, France). He was the recipient of a Howard Hughes fellowship for physician and spent four years in Washington University, St Louis, MO, USA as a postdoctoral fellow and a research assistant professor. From 1997, he was a researcher of the French National Research Institute (INSERM) and in 2003 he obtained a position of professor of Biochemistry at the Medical School of Montpellier (France). His research focuses on neurodegenerative disorders (Alzheimer, Prion..) and on clinical proteomics. He is a vice-president of the French National Society of Clinical Biology (SFBC) in charge of its Scientific Committee and he chairs the Working Group "Clinical Quantitative Mass Spectrometry Proteomics" of the International Federation of Clinical Chemistry and Laboratory Medicine (IFCC).
80. MacLean B, Tomazela DM, Shulman N, Chambers M, Finney GL, Frewen B, et al. Skyline: an open source document editor for creating and analyzing targeted proteomics experiments. Bioinformatics 2010;26:966-8.

81. Schilling B, Rardin MJ, MacLean BX, Zawadzka AM, Frewen BE, Cusack MP, et al. Platform-independent and label-free quantitation of proteomic data using MS1 extracted ion chromatograms in skyline: application to protein acetylation and phosphorylation. Mol Cell Proteomics 2012;11:202-14.

82. Prakash A, Tomazela DM, Frewen B, Maclean B, Merrihew G, Peterman S, et al. Expediting the development of targeted SRM assays: using data from shotgun proteomics to automate method development. J Proteome Res 2009;8:2733-9.

83. Gerber SA, Rush J, Stemman O, Kirschner MW, Gygi SP. Absolute quantification of proteins and phosphoproteins from cell lysates by tandem MS. Proc Natl Acad Sci USA 2003;100:6940-5.

84. Beynon RJ, Doherty MK, Pratt JM, Gaskell SJ. Multiplexed absolute quantification in proteomics using artificial QCAT. proteins of concatenated signature peptides. Nat Methods 2005;2:587-9.

85. Wehr AY, Hwang WT, Blair IA, Yu KH. Relative quantification of serum proteins from pancreatic ductal adenocarcinoma patients by stable isotope dilution liquid chromatography-mass spectrometry. J Proteome Res 2012;11:1749-58.

86. Brun V, Dupuis A, Adrait A, Marcellin M, Thomas D, Court M, et al. Isotope-labeled protein standards: toward absolute quantitative proteomics. Mol Cell Proteomics 2007;6:2139-49.

87. Bland JM, Altman DG. Statistical methods for assessing agreement between two methods of clinical measurement. Lancet 1986;1:307-10.

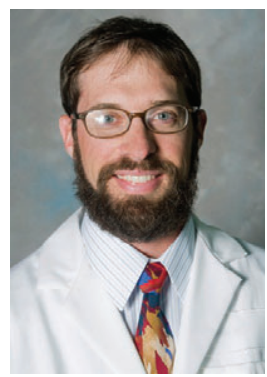

Andy Hoofnagle, MD, PhD, is a board certified clinical pathologist and serves as the Director of Clinical Mass Spectrometry and the Assistant Director of the Clinical Chemistry and Clinical Immunology Laboratories at the University of Washington. His laboratory has helped pioneer the use of liquid chromatography-tandem mass spectrometric methods in the quantification of proteins in serum and plasma, including the use of peptide immunoaffinity enrichment prior to LC-MS/MS for the quantification of low abundance proteins. His laboratory also studies mechanisms of cardiovascular disease. 


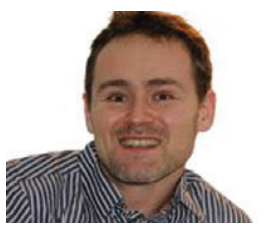

Cato Brede, Analytical Chemist, PhD, MSc. From 2005 until present time, Dr. Brede has been working at Stavanger University Hospital, where he is responsible for analytical method development using robotic pipetting and LC-MS/MS. He has experiences in both routine analysis (drugs of abuse, homocysteine, methylmalonic acid, 25-hydroxy-vitamin D, etc.) and in research analysis (polymer monolithic column preparation for proteins and peptides, oxidative stress markers, preparation of immunoaffinity adsorbent for HAP depletion, etc.). In the period 1999-2004, Dr. Brede worked at the Regional Food Control Authority in Stavanger, later to become part of the Norwegian Food Control Authority. He developed several methods for detecting migration of chemical substances from plastic food packaging into food and food simulants. By using instrumentation such as GC-MS and HPLC, he was able to measure migration of substances such as bisphenol A/F diglycidyl ether, bisphenol A, primary aromatic amines, and n-ethyl-sulfonamides. In this period he also developed a method for quantification of acrylamide in foodstuffs and cosmetics. In the period 1989-1999 he studied at University of Oslo, where he achieved the final degree of $\mathrm{Dr}$. Scient. (PhD) in chemistry based on 5 publications and one patent (WO/1998/036440), and with the dissertation entitled: "Gas chromatography coupled with microplasma mass spectrometry."

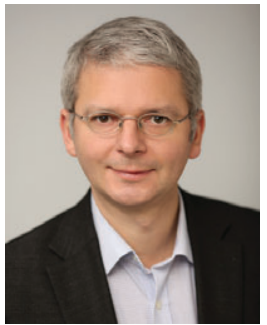

Dr. Matthias Glueckmann, born in 1970, studied chemistry at the University of Frankfurt where he received his PhD in the workgroup of Prof. Dr. Michael Karas in 2001. From 2001 to 2011 he held various positions in support for mass spectrometer and HPLC instruments mainly focusing on the analysis of peptides and proteins, proteomics application and biomarker research. Currently he holds a position as Service Territory Specialist Eksigent Products at AB SCIEX. He is the author or co-author of more than 30 peer-reviewed publications.

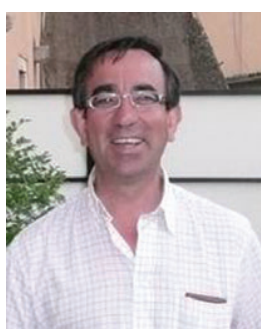

José A. Cocho de Juan obtained his PhD in Chemistry from the University of Santiago de Compostela (USC). Clinical Biochemist in "Laboratorio de Metabolopatias" at University Hospital of Santiago from 1980. His research interests are related to newborn screening, uses of mass spectrometry techniques in laboratory medicine, inborn errors of metabolism, metabolomics and trace elements. Member of the Board in the Spanish Society for Clinical Biochemistry and Molecular Pathology, SEQC.

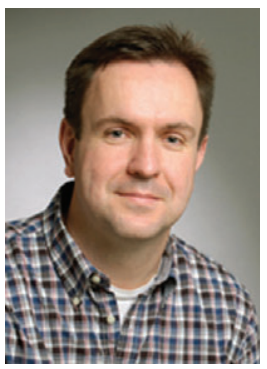

Christof Lenz is a Senior Scientist at the Max Planck Institute for Biophysical Chemistry (MPIbpc) and the University Medical Center (UMG) in Göttingen, Germany. After graduating as Dr. rer. nat. from the University of Cologne, he worked for 12 years in various roles for a manufacturer of mass spectrometry equipment before moving back into academic research. Christof has extensive experience in the mass spectrometric analysis of peptides and proteins, including the identification and quantitation of protein biomarkers. He is the author or co-author of more than 25 peer-reviewed publications.

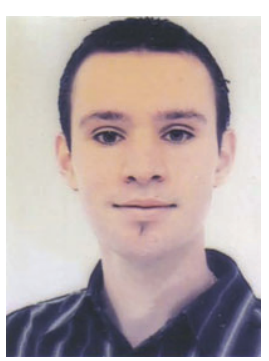

J. Vialaret was born in 1984 and studied Organic Chemistry at Montpellier II University (Master degree in 2007). Specialization in proteomic was made through jobs in Pierre Fabre Laboratories, EPFL (Lausanne, Switzerland), INRA (Montpellier, France) before having a position at the CHU Montpellier hospital. After large-scale proteomics (proteome and phosphoproteome) with dedicated quantitative methods (silac and label-free), he focused on the development of protein quantification using targeted mass spectrometry in a clinical environment. He is in charge of these method developments in the Clinical Proteomic Platform of the Laboratory of Biochemistry and Clinical Proteomic directed by Pr. Sylvain Lehmann in Montpellier. 


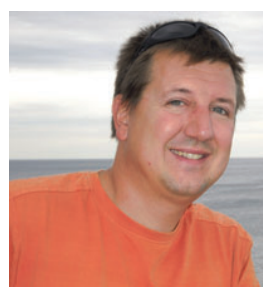

Alexander Scherl obtained his PhD in chemistry from the University of Geneva, Switzerland in 2005. After a three years post-doctoral fellowship in Seattle, WA, he went back to Geneva were he headed the Proteomics Core Facility at the Faculty of Medicine until 2011.

Since then, he is primary investigator at the Swiss Center for Applied Human Toxicology (scaht.org) and in charge of translational mass spectrometry projects at the Faculty of Medicine, University of Geneva.

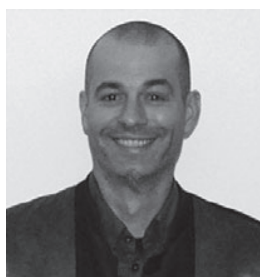

C. Hirtz was born in 1972 and studied Biochemistry at Paul Sabatier University in Toulouse. Titular of a Doctorate and an accreditation to supervise research in the proteomics field, he is associate professor at the University Montpellier I and is specialized in biochemistry and proteomics. His scientific interest includes the development of new method of protein quantification using targeted mass spectrometry in a clinical environment. He is in charge of the Clinical Proteomic Plateform of the Laboratory of Biochemistry and Clinical Proteomic directed by Pr. Sylvain Lehmann in Montpellier. 